\title{
Effect of Propafenone on the Contractile Activity of Latissimus Dorsi Muscle Isolated in an Organ Chamber. Experimental Study in Rats
}

\author{
Ricardo Simões, Eduardo Luis Guimarães Machado, Odilon Gariglio de Alvarenga Freitas, \\ Maria da Consolação Vieira Moreira, Otoni Moreira Gomes
}

Belo Horizonte, MG - Brazil

Objective - To study the effect of propafenone on the contractile function of latissimus dorsi muscle isolated from rats in an organ chamber.

Methods - We studied 20 latissimus dorsi muscles of Wistar rats and divided them into 2 groups: group I $(n=10)$, or control group - we studied the feasibility of muscle contractility; group II $(n=10)$, in which the contralateral muscles were grouped - we analyzed the effect of propafenone on muscle contractility. After building a muscle ring, 8 periods of sequential 2-minute baths were performed, with intervals of preprogrammed electrical stimulation using a pacemaker of 50 stimuli/min. In group II, propafenone, at the concentration of $9.8 \mu \mathrm{g} / \mathrm{mL}$, was added to the bath in period 2 and withdrawn in period 4.

Results - In group I, no significant depression in muscle contraction occurred up to period 5 ( $p>0.05$ ). In group II, a significant depression occurred in all periods, except between the last 2 periods $(p<0.05$ ). Comparing groups I and II only in period 1, which was a standard period for both groups, we found no significant difference $(p>0.05)$.

Conclusion-Propafenone had a depressing effecton the contractile function of latissimus dorsi muscle isolated from rats and studied in an organ chamber.

Keywords: skeletal muscle/drug effect, propafenone/toxicity, cardiomyoplasty

Fundação Cardiovascular São Francisco de Assis - Hospital São Francisco de Assis Mailing address: Otoni Moreira Gomes - Rua Jacuí, 1191 - 31110-050 - Belo Horizonte, MG, Brazil - E-mail:

English version by Stela Maris C. e Gandour
One aspect of myocardial failure syndrome is the progressive loss of systolic function, and, therefore, dilation of the cardiac cavities; the results obtained with the pharmacological treatment are not totally satisfactory ${ }^{1-10}$. In an attempt to increase systolic contraction, pedicled flaps of skeletal muscle involving the heart were projected.

In 1985, Carpentier and Chachques ${ }^{11}$ reported the first cardiomyoplasty with successful clinical evolution. Latissimus dorsi (LD) muscle was chosen because it is wide enou$\mathrm{gh}$, is conveniently located, and is easily mobilized towards the inside of the chest. Another advantage is its long vascular-nervous pedicle, which facilitates electrical conditioning with a pacemaker, and the presence of the thoracodorsal nerve specifically developed for cardiomyoplasty ${ }^{12,13}$. This procedure is mainly indicated for patients with New York Heart Association functional class III congestive heart failure, because it provides a myocardial compression effect and also prevents progressive cardiac dilation ${ }^{11,14,15}$. Even though a low degree of atrophy and a drop in tension was found in LD muscle, resistance to fatigue was significantly increased when it was electrically conditioned. Adaptation of the skeletal muscle is confirmed by a complete histological transformation, in which the rapid-contraction fibers acquire all the physiological, biochemical, and morphological attributes of the slow-contraction fibers ${ }^{13,16-18}$.

Considering that patients with congestive heart failure have an increased incidence of arrhythmias and a higher risk of sudden death, some of them may require antiarrhythmic drugs. Some large studies about the action of antiarrhythmic drugs showed proarrhythmic effects and a myocardial depressing effect of some of these drugs, leading to an increase in mortality ${ }^{19-23}$. These effects occurred mainly with drugs of the Ic group ${ }^{24}$, such as propafenone, which is frequently used in clinical practice ${ }^{25-29}$. Would the skeletal muscle involving the heart be influenced by the depressing action of antiarrhythmic drugs? The objective of our study 
was to analyze the effects of propafenone [2'-2 hydroxy -3(propylamine) - propoxy -3 phenylpropylfenone chloride].

\section{Methods}

We used 10 male Rattus norvegicus of the Wistar variety, with ages ranging from 18 to 24 weeks, and weight from 320 to $360 \mathrm{~g}$ (mean $=340 \pm 14.53 \mathrm{~g}$ ). They were divided into 2 groups as follows: group I - $10 \mathrm{LD}$ muscles were isolated with a mean weight of $1.25 \pm 0.09 \mathrm{~g}$ and were used as controls; group II - 10 LD muscles were isolated with a mean weight of $1.27 \pm 0.103 \mathrm{~g}$ and were studied after addition of propafenone to the perfusion solution. We used, alternately, one of the muscles as group I and that of the opposite side as group II. The rats were anesthetized with diethyl ether in a fume cupboard, and their mean time of anesthetic induction was $14 \pm 5$ minutes.

We used Krebs-Henseleit solution bubbled in a carbonic mixture to maintain muscle feasibility $\left(95 \% \mathrm{O}_{2} \text { and } 5 \% \mathrm{CO}_{2}\right)^{30}$.

For measurements and recordings, we used the GRAS$\mathrm{S} \circledast$ transducer (USA) FT 03 model, and a BESE-Bio III biomonitor(MG, Brazil).

Electrical stimulation was performed with a BRASCOR 12 pacemaker with the following programming: frequency of 50 stimuli/minute, pulse amplitude of $20 \mathrm{~mA}$, and pulse width of 0.5 milliseconds.

We used the Cleveland Clinic Foundation model (USA) organ chamber with a volume capacity of $25 \mathrm{~mL}$ for the nourishing solution and a thermoregulated bath, HCFM-USP model(SP, Brazil).

We isolated the LD muscles bilaterally and implanted pacemaker electrodes in 2 distinct anatomical planes. In the superior surface of the muscle, 1 electrode was fixed along the extension of that plane with 3 suture stitches (nylon 5-0) and connected to the positive pole of the electrical stimulator. In the inferior surface of the muscle, the $2^{\text {nd }}$ electrode was fixed along the entire circular extension of the ring and connected to the negative pole.

The muscular ring was modeled using the interposition of an acrylic tube, which was surrounded by the LD muscle. After the electrodes were positioned, the mold was removed, and the insertion of the muscle in the scapula was sectioned. Then, the muscle ring was fixed in the organ chamber by traction straps in the inferior rod and in the tensiometer, in its superior part (fig. 1) ${ }^{30}$. The mean time elapsed from muscle dissection and isolation until its positioning in the organ chamber was 5.0 \pm 2.0 minutes.

As we could not find any previous report about the technique in the consulted literature, we performed the baths with 8 periods of 2 minutes each for obtaining adequate readings for analysis.

The periods consisted of immersion of the muscular ring in previously warmed Krebs-Henseleit solution bubbled in a carbonic mixture ${ }^{31}$, where the muscular ring was maintained at rest for 2 minutes. Then, the muscular structure was removed from the solution to avoid multifocal depolarization and electrical stimulation. After stabilizing the tracing, the contractile muscle force was recorded. We used

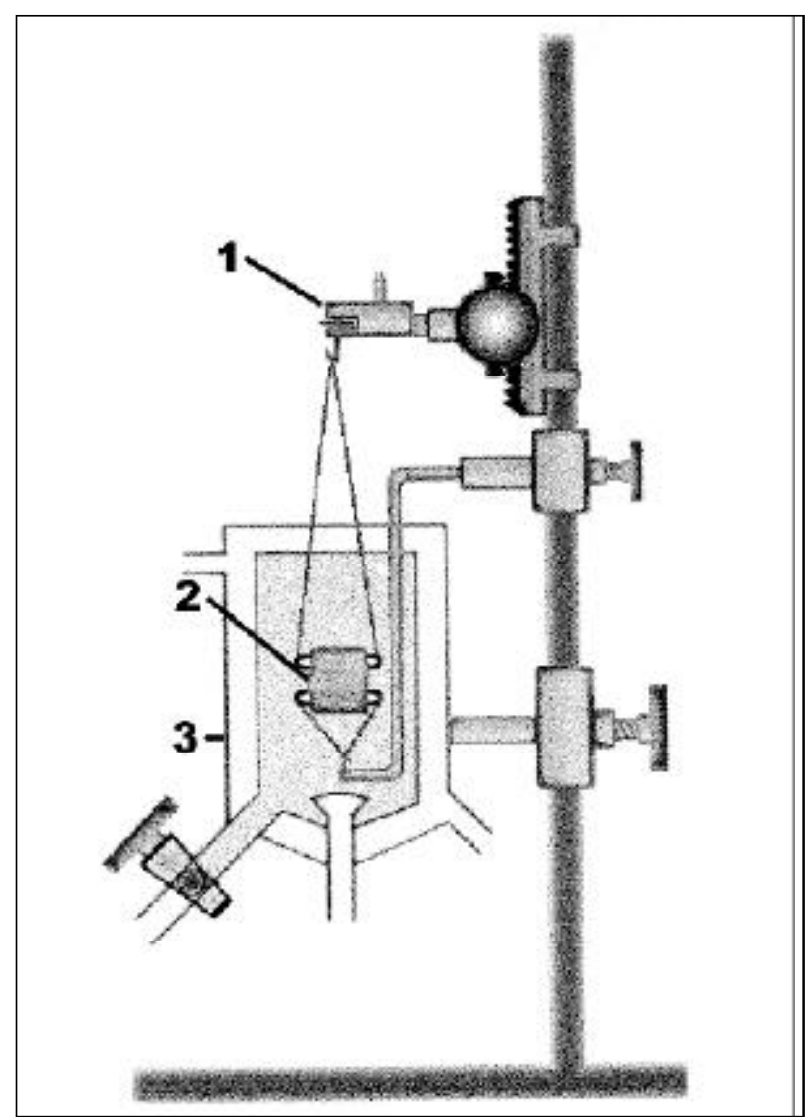

Fig.1 - Sketch fo the tesiometer (1) with te muscle ring (2) positioned in the organ chamber(3).

calibration with equivalence of $1.0 \mathrm{~cm}$ to $2.0 \mathrm{~g}$ of tension (22$\mathrm{X}$ amplification) and recorded 3 deflections for measurement; this way, we obtained the mean of the addition of the readings and tabulation of data for analysis. Period 1 was common for the 2 groups. For group II, propafenone $(245 \mu \mathrm{g})$ was added to the perfusion solution in the bath of period 2, and this was done according to the recommended dosage of propafenone for arrhythmia conversion in bolus of 1 to $2 \mathrm{mg} / \mathrm{kg}$. Period 3 consisted of maintaining the same solution of period 2, without or with propafenone for groups I or II, respectively. From period 4 on, the bathing solutions were successively changed until period 8 , aiming to promote washing of the drug, when it was present. This procedure was the same for both groups.

At the end of each experiment, the rats and muscles were weighed separately. At the end of periods 1 and 3, the solution present inside the chamber was collected for gas analysis and $\mathrm{pH}$ determination for both groups.

In the statistical analysis, we used the following methods: analysis of variance, Duncan multiple range test (for multiple comparisons), and the least significant difference (LSD) test (for comparing mean values).

\section{Results}

The comparative analysis of the tensions developed by the muscles in group I in the different periods showed no 
significant difference until period 4 ( $p>0.05)$ (tab. I). These data also showed the nonexistence of the so-called "solution effect." That is, the solution maintained between periods 2 and 3 did not influence the contractile muscle force $(\mathrm{p}>0.05)$. From period 5 to period 8 , the drop was significant with $\mathrm{p}<0.05$ (tab. I).

Group II exhibited a significant drop in contractile muscle force from period 2 on ( $\mathrm{p}<0.05)$, except for the last 2 periods ( $p>0.05)$ (tab. I).

Figure 2 depicts the means with their respective standard errors, and the difference between the 2 groups can be seen with a more marked drop in the contractile muscle force in group II $(\mathrm{p}<0.05)$.

When comparisons of the percentage drop in contractile muscle force were performed between 2 subsequent periods for group I in regard to group II (fig. 3), we observed that this drop occurred until the last period of the experiment. The mean percentage of total drop was $45.3 \%$ for group I and $65.4 \%$ for group II.

\section{Discussion}

Left ventricular ejection fraction is one of the major predictors of survival in the analysis of heart disorders, and its drop results from cardiac dilation ${ }^{19,32,33}$. Some studies showed the efficacy in generating systolic force by surrounding the heart with muscular flaps ${ }^{11,14}$. Several experiments showed the capacity to replace cardiac muscle force, as a pump, synchronous with the QRS complex ${ }^{11,14,34-41}$.

Data in the literature have shown that drugs with a primary cardiac effect also act upon skeletal muscle modifying its function ${ }^{42-44}$. Dubelaar et $\mathrm{al}^{42}$ studied the effect of L-carnitine on LD muscle of dogs and showed an increase in its contractile force. Other drugs, such as the steroids methenolon and clenbuterol, may increase skeletal muscle mass and contractile force when associated with the cardiomyoplasty technique ${ }^{43,44}$. Howell et al ${ }^{45}$ showed the effects of some drugs, such as isoproterenol, acting on skeletal muscle and producing positive inotropism in the rapid-contraction fibers and negative inotropism in the slow-contraction fibers. They also showed that aminophylline and theophylline have an effect on skeletal muscle, which was evidenced through muscle tremor, mainly postural.

Propafenone belongs to the Ic class of antiarrhythmic drugs $^{24}$. Its clinical use began in the 1980 s due to its characteristics as a local anesthetic and stabilizer of myocardial cell membrane. Propafenone has been shown to reduce the amplitude of the action potential (phase 0 ), the conduction in the

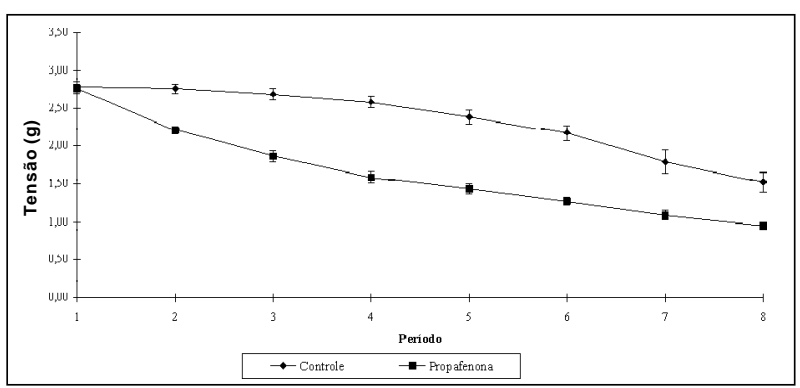

Fig. 2 - Mean values of the tensions of muscle contractions in groups I and II.

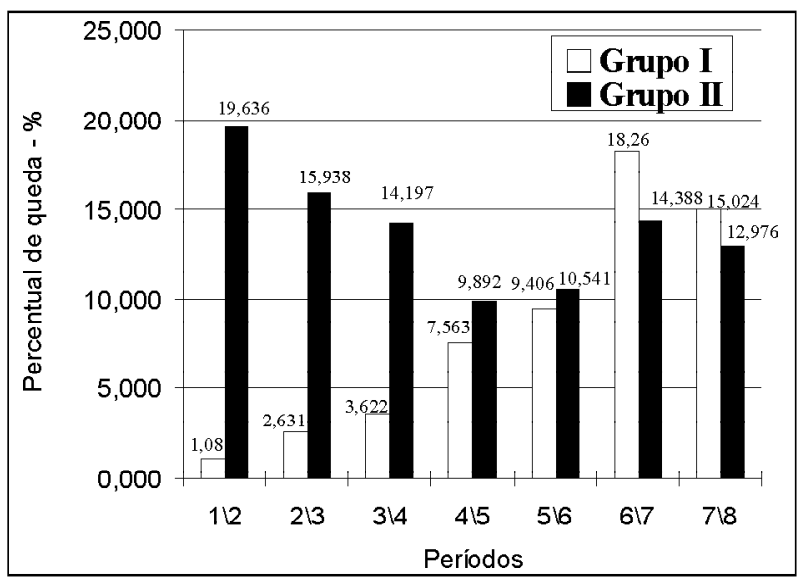

Fig. 3 - Percentage variation of the drop in muscle contraction between the periods for groups I and II.

atrioventricular node, and the ascending velocity of the curve of spontaneous diastolic depolarization (phase 4). Depending on the metabolic pathway of hydroxylation of propafenone, different levels of its metabolites (5 - hydroxypropafenone and $\mathrm{N}$-dipropylpropafenone) may result, promoting a mild beta-blocking action ${ }^{45-47}$. Propafenone has a predominantly inhibitory effect on sodium $\left(\mathrm{Na}^{+}\right)$channels, and a less effective impact on calcium $\left(\mathrm{Ca}^{++}\right)$and potassium $\left(\mathrm{K}^{+}\right)$ channels ${ }^{24,25}$. In reality, its effect on calcium $\left(\mathrm{Ca}^{++}\right)$channels was considered nonsignificant. However, the hypothesis that this might be the probable cause of myocardial depression was raised, leading to an increase in final diastolic pressure $\left(\mathrm{DP}_{2}\right)$ and a reduction in systolic indices ${ }^{26-28}$.

Some studies have shown the effect of propafenone on vascular smooth muscle relaxation after endothelial skeletonizing, confirming its depressing action on the muscle ${ }^{29}$. In 1987, Fierro et al ${ }^{48}$ reported 1 case of myasthenia-like syndrome induced by propafenone, but they did not define the drug's action on neuromuscular receptors and myofibrils.

\begin{tabular}{|c|c|c|c|c|c|c|c|c|}
\hline & & & & Period & & & & \\
\hline Group & $1^{\circ}$ & $2^{\circ}$ & $3^{\circ}$ & $4^{\circ}$ & $5^{\circ}$ & $6^{\circ}$ & $7^{\circ}$ & $8^{\circ}$ \\
\hline I & 2.78 & $2.75^{(*)}$ & $2.68^{(*)}$ & $2.58^{(*)}$ & $2.39^{(*)}(* *)$ & $2.17^{(*)}(* *)$ & $1.79^{(*)}(* *)$ & $1.52^{(*)(* *)}$ \\
\hline II & 2.75 & $2.21^{(*)(* *)}$ & $1.86^{\left.(*))^{* * *}\right)}$ & $1.59^{(*)(* *)}$ & $1.43^{(*)(* *)}$ & $1.27^{(*)(* *)}$ & $1.09^{(*)}$ & $0.95^{(*)}$ \\
\hline
\end{tabular}


Some animal species have pharmacokinetic characteristics related to the tendency towards a concentration rate (plasma/tissue) below 1 at the skeletal muscle, showing that them uscleserves as adnugreservoir ${ }^{49}$.

A great variety of acute and chronic pathophysiological and pharmacological factors may cause changes in skeletal muscle contraction and fatigue and in its adaptive responses ${ }^{42-45}$. These facts indirectly support the results obtained in the present study.

Rats were the animals chosen for our study because of the size of and also the constitution of the latissimus dorsi muscle to be analyzed in our study. In small animals, this muscle has a larger number of type I fibers, because it requires a greater resistance to fatigue, as the animals perform repetitive movements more frequently.

Side alternation, left and right, for muscles in groups I or II aimed to alter the disposition of muscle fibers for the confection of the muscle ring, so that muscle feasibility would be the same, independent of the side.

A constant temperature of $37^{\circ} \mathrm{C}$, with a variation of $0.5^{\circ} \mathrm{C}$, was maintained, and it was measured in real time with a catheter inserted into the bath solution, reflecting the baseline levels of the species studied ${ }^{39}$. The $\mathrm{pH}$ of the medium was maintained even after addition of propafenone, because metabolic acidosis reduced the drug's action; however, variations within physiological limits were respected ${ }^{50,51}$.

In the study of the action of propafenone, when the analysis of variance indicated a depressing effect, the least significant difference test for comparing mean values was used to evaluate this effect between the different periods. The interaction, when significant, indicated the existence of differences in the behavior of the muscle for each period when periods were compared with one another.

In group I, no significant ( $\mathrm{p}>0.05$ ) drop in muscle contraction was observed until period $4(2.78 \mathrm{~g}, 2.75 \mathrm{~g}, 2.68 \mathrm{~g}$, $2.58 \mathrm{~g}$, respectively); from period $5 \mathrm{on}$, the reduction in contractile force became significant $(\mathrm{p}<0.05)(2.39 \mathrm{~g}, 2.17 \mathrm{~g}$, $1.79 \mathrm{~g}, 1.52 \mathrm{~g}$, respectively). This may be justified by the progressive loss of muscle feasibility during the experiment. In group II, after addition of propafenone in period 2, a drop in muscle contraction could be observed until period $7(p<0.05)$ $(2.75 \mathrm{~g}, 2.21 \mathrm{~g}, 1.86 \mathrm{~g}, 1.59 \mathrm{~g}, 1.43 \mathrm{~g}, 1.27 \mathrm{~g}, 1.09 \mathrm{~g}$, respectively); no difference between the last 2 periods was observed ( $p>0.05$ ) $(1.09 \mathrm{~g} ; 0.95 \mathrm{~g}$, respectively). One of the hypotheses would be the possible washing away of propafenone impregnated in LD muscle through the consecutive baths performed. Another hypothesis is the progressive loss of muscle feasibility with a drop in contractile force, even when immersed in a solution adequate for study.

In regard to the Krebs-Henseleit solution, which is considered adequate for maintaining muscle feasibility, we analyzed the possibility that it could cause alterations in the results, the so-called "solution effect." To check the effect of the solution on the experiment, the analysis of variance of the results of the means obtained in periods 2,3 , and 4 was performed. In the protocol established, the change of solution between periods 2 and 3 in both groups was not performed, and the action of propafenone was maintained for approximately 5 minutes. Therefore, we admit that no influence of the solution occurred on the results, because group I maintained the stability when the means were compared until period $4(\mathrm{p}>0.05)$.

In the multiple comparison of the means of the different periods between the groups, we could not reject the hypothesis of equality in the first period only, because it was common to both groups. From period 2 on, the difference was maintained significantly until the end of the experiment $(\mathrm{p}<0.05)$.

In regard to LD muscle contractile force, the evaluation of the percentage of its total drop was $45.3 \%$ in group I and $65.4 \%$ in group II, evidencing a greater percentage of drop with the use of propafenone.

Considering the limitations of the present study, we may conclude that propafenone determines depression of the LD muscle contractile force in rats, with depression of muscle contraction with no recovery, even after sequential baths with a solution with no drug; the use of propafenone, in an acute administration regimen, may affect muscle performance in the cardiomyoplasty technique. Therefore, the control of ventricular function in patients undergoing cardiomyoplasty and requiring the use of propafenone should be carefully observed during the impregnation phase to decide about risks and benefits.

Based on the results of this study, the following facts should be considered because they may constitute obstacles to the immediate clinical application of this technique: LD muscle did not undergo proper preconditioning in the cardiomyoplasty technique; the different types of fibers that constitute LD muscle would be under the influence of the differentiated action of propafenone, as well as that of the dose being used; we still lack adequate definitions of the interference of the species-dependent characteristics for generalizing the conclusions.

\section{References}

1. Kannel WB, Belanger AJ. Epidemiology of heart failure. Am Heart J 1991; 121: 951-7.

2. Benedict CR, Weiner DH, Johnstone DE, et al. Comparative neurohormonal response in patients with preserved and impaired left ventricular ejection fraction: Results of the Studies of Left Ventricular Dysfunction (SOLVD) Registry. The SOLVD Investigators. J Am Coll Cardiol 1993; 22: 146A-53A.
3. Setaro JF, Soufer R, Remetz MS, Perlmutter RA, Zaret BL. Long-term out-come in patients with congestive heart failure and intact systolic left ventricular performance. Am J Cardiol 1992; 69: 1212-6.

4. Cohn JN, Archibald DG, Francis GS, et al. Veterans Administration Cooperative Study on vasodilator therapy of heart failure: influence of prerandomization 
variables on the reduction of mortality by treatment with hydralazine and isosorbide dinitrate. Circulation 1987; 75: IV-49-54.

5. The CONSENSUS Trial Study Group. Effects of enalapril on mortality in severe congestive heart failure. N Engl J Med 1987; 316: 1429-35.

6. Swedberg K, Held P, Kjekshus J, Rasmussen K, Rydén L, Wedel H. Effects of the early administration of enalapril on mortality in patients with acute myocardial infarction. Results of the Cooperative New Scandinavian Enalapril Survival Study II (CONSENSUS II). N Engl J Med 1992; 327: 678-84.

7. The SOLVD Investigators. Effect of enalapril on mortality and the development of heart failure in assyntomatic patients with reduced left ventricular ejection fractions. N Engl J Med 1992; 327: 685-9.

8. Cohn JN, Johnson G, Ziesche S, et al. A comparison of enalapril with hydralazine-isosorbide dinitrate in the treatment of chronic congestive heart failure. $\mathrm{N}$ Engl J Med 1991; 325: 303-10.

9. Pfeffer MA, Brawnwald E, Moyé LA, et al. Effect of captopril on mortality and morbidity in patients with left ventricular dysfunction after myocardial infarction: results of the Survival and Ventricular Enlargement Trial. N Engl J Med 1992; 327: 669-77.

10. Schwarz F, Mall G, Zebe H, et al. Determinants of survival in patients with congestive cardiomyopathy: quantitative morfologic findings and left ventricular hemodynamics. Circulation 1984; 70: 923-8.

11. Carpentier A, Chachques JC. Myocardial substitution with a stimulated skeletal muscle: first successful clinical case (letter). Lancet 1985; 1: 1267.

12. Magovern GJ, Park SB, Christlieb IY, Magovern Jr GJ, Kao RL. Paced conditioned latissimus dorsi for cardiac assist. In: Chiu RC-J, Bourgeois IM, editors Transformed Muscle for Cardiac Assist and Repair. New York: Futura Publishing Co. Inc., 1990: 199

13. Salmons S, Sréter FA. Significance of impulse activity in transformation of skeletal muscle type. Nature 1976; 263: 30-4.

14. Chiu RC-J, editor. Biomechanical Cardiac Assist: Cardiomyoplasty and Muscle Powered Devices. New York: Futura Publishing Co. Inc.,1986.

15. Carpentier A, Chachques JC, Grandjean PA. Cardiomyoplasty. $1^{\text {st }}$ ed. Mount Kisco (NY): Futura Publishing Co. Inc., 1991.

16. Havenith MG, van-der-Veen FH, Glatz JFC, et al. Monitoring of muscle fiber type of canine Latissimus dorsi muscle during chronic electrical stimulation by enzyme- and immunohistochemistry. In: Chiu RC-J, Bourgeois IM, editors. Transformed Muscle for Cardiac Assist and Repair. New York: Futura Publishing Co. Inc., 1990: 53.

17. Henriksson J, Salmons S, Lowry OH. Chronic stimulation of mamaliam muscle: enzyme and metabolite changes in homogenates and individual fibers. In: Chiu RC-J, Bourgeois IM, editors. Transformed Muscle for Cardiac Assist and Repair. New York: Futura Publishing Co. Inc., 1990: 9.

18. Mannion JD, Shannon J, Chen W, Brown WE, Gale DR. Skeletal muscle-powered assistance for the heart: assessment of a goat model. In: Chiu RC-J, Bourgeois IM, editors. Transformed Muscle for Cardiac Assist Repair. New York: Futura Publishing Company, Inc., 1990: 117.

19. Kannel WB, Plehn JF, Cupples LA. Cardiac failure and sudden death in the Framingham study. Am Heart J 1988; 115: 869-75.

20. CAST Investigators. Prelimirary report: effect of encainide and flecainide on mortality in a randomized trial of arrhythmia suppression after myocardial infarction. N Engl J Med 1989; 321: 406-12.

21. Siebels J, Kuck KH and the CASH Investigators. Implantable cardioverter defibrillator compared with antiarrhythmic drug treatment in cardiac arrest survivors (the Cardiac Arrest Study Hamburg). Am Heart J 1994;1 27: 1139-44.

22. Multicenter Posinfarction Research Group. Risk stratification and survival after myocardial infarction. N Engl J Med 1983; 309: 331-6.

23. Batsford WP, Mickleborough LL, Elefteriades JA. Cardiac arrhythmias in the heart failure. Cardiol Clinics. Ed. Philadelphia: WB Saunders 1995; 1: 87.

24. Vaughan Williams EM. Significance of classifying antiarrhythmic actions since the cardiac arrhythmia suppression trial. J Clin Pharmacol 1991; 31: 123-35.

25. Dukes ID, Vaughan Williams EM. The multiple modes of action of propafenone. Eur Heart J 1984; 5: 115-25.

26. Baker BJ, Dinh H, Kroskey D, de Soyza NDB, Murphy ML, Franciosa JA. Effect of propafenone on left ventricular ejection fraction. Am J Cardiol 1984; 54: 20D-2.

27. Lange H, Lampert S, Sutton MSJ, Lown B. Changes in cardiac output determined by continuous-wave doppler echocardiography during propafenone or mexiletine drug testing. Am J Cardiol 1990; 65: 458-62.
28. Santinelli V, Arnese M, Oppo I, et al. Effects of flecainide and propafenone on systolic performance in subjects with normal cardiac function. Chest 1993; 103: 1068-73.

29. Vizcaino FP, Pozo BF, Zaragoza F, Tamargo J. Voltage-and time-dependent inhibitory effects on rat aortic and porcine coronary artery contraction induced by propafenone and quinidine. Br J Pharmacol 1994; 113: 1281-8.

30. Gomes OM, Simões R, Machado ELG, Freitas OGA, Brum JMG. Técnica para estudo do músculo latissimus dorsi de pequenos animais em câmara de órgãos. Coração 1996, 6: 30-5.

31. Krebs HA, Henseleit K. Untersuchungen ober die Hanstoffbildung in tierkoper. Hope Seyler Z. Physiol. Chem., 210-30; 1932 Apud in the isolated perfused warm-blooded heart according to the LANGENDORFF - Doring HJ, Dehnert H: Methods in Experimental Physiology and Pharmacology. Preprint of the $1^{\text {st }}$ English Edition; 1987.

32. Glover DR, Littler WA. Factors influencing survival and mode of death in severe chronic ischemic cardiac failure. Br Heart J 1987; 57: 125-32.

33. Gradman A, Deedwania P, Cody R, et al. Predictor of total mortality and sudden death in mild to moderate heart failure. J Am Coll Cardiol 1989; 14: 564-70.

34. Moreira LFP, Stolf NAG, Bocchi EA, et al. Latissimus dorsi cardiomyoplasty in the treatment of pacients with dilated cardiomyopathy. Circulation 1990; 82: IV257-63.

35. Cheng W, Justicz AG, Soberman MS, Alazraki NP, Santamore WP, Sink JD. Effects of dynamic cardiomyoplasty on indices of left ventricular systolic and diastolic function in canine model of chronic heart failure. J Thorac Cardiovasc Surg 1992; 103: 1207-13.

36. Aklog L, Murphy MP, Chen FY, et al. Right latissimus dorsi cardiomyoplasty improves function by increasing peak systolic elastance (Emax). Ciculation 1994; 90: II- 112-9.

37. Jondeau G, Dorent R, Bors V, et al. Dynamic cardiomyoplaty. effect of descontinuing latissimus dorsi muscle stimulation on left ventricular systolic and diastolic performance and exercise capacity. J Am Coll Cardiol 1995; 26: 129-34.

38. Schreuder JJ, van der Veen FH, van der Velde ET, et al. Beat-to-beat analysis of left ventricular pressure-volume relation and stroke volume by condutance catheter and aortic modelflow in cardiomyoplasty patients. Circulation 1995; 91: 2010-7.

39. Moreira LFP, Bocchi EA, Stolf NAG, Pileggi F, Jatene AD. Current expectations in dynamic cardiomyoplasty. Ann Thorac Surg 1993; 55: 299-303.

40. Hagège $\mathrm{AA}$, Desnos M, Fernadez F, et al. Clinical study of the effects of latissimus dorsi muscle flap stimulation after cardiomyoplasty. Circulation 1995; 92: II-210-5.

41. Kratz JM, Johnson WS, Mukherjee R, Hu J, Crawford FA, Spinale FG. The relation between latissimus dorsi skeletal muscle structure and contractile function after cardiomyoplasty. J Thorac Cardiovasc Surg 1994; 107: 868-78.

42. Dubelaar ML, Lucas CM, Hülsmann WC. Acute effect of L-carnitine on skeletal muscle force test in dogs. Am J Physiol 1991; 260: E-189-93.

43. Petrou M, Wynne DG, Boheler KR, Yacoub MH. Clembuterol induces hypertrophy of the latissimus dorsi muscle and heart in rat with molecular and phenotypic changes. Circulation 1995; 92: II-483-9.

44. Fritzsche D, Krakor R, Asmussen G, et al. Effect of an anabolic steroid (metenolon) on contractile performance of the chronically stimulates latissimus dorsi in sheep. Eur J Cardiothorac Surg 1994; 8: 214-9.

45. Howell S, Fitzgerald RS, Shnader J, Roussos C. Contratility and fatigue in skeletal muscle: influence of pathophysiological and pharmacological interventions. In: Chiu RC-J, Bourgeois IM, editors. Transformed muscle for cardiac assist repair. New York: Futura Publishing Co. Inc., 1990: 75.

46. Barbey JT. Clinical pharmacology and beta-blocking efficacy of propafenone. J Cardiovasc Pharmacol 1991; 17: S-41-3.

47. Malfatto G, Pessano P, Zaza A, Schwartz PJ. Experimental evidence for beta adrenergic blocking properties of propafenone and for their potential clinical relevance. Eur Heart J 1993; 14: 1253-7.

48. Fierro B, Castiglione MG, Salemi G. Myasthenia-like syndrome induced by cardiovascular agents: report of a case. Ital J Neurol Sci 1987; 8: 167-9.

49. Steurer $\mathrm{G}$, Weber $\mathrm{H}$, Schmidinger $\mathrm{H}$, et al. Plasma propafenone concentration in the evaluation of anti-arrhythmic efficacy. Eur Heart J 1991; 12: 526-32.

50. Gillis AM, Kates RE. Effect of $\mathrm{pH}$ on the myocardial uptake and pharmacodynamics of propafenone in the isolated rabbit heart. J Cardiovasc Pharmacol 1988; 12: 526-34.

51. Gillis AM, Keashly R. Myocardial uptake and pharmacodynamics of quinidine and propafenone in isolated rabbit hearts: metabolic versus respiratory acidosis. J Cardiovasc Pharmacol 1991; 17: 532-8. 